\title{
Announcement
}

\section{The Bernd Tersteegen Award}

The Bemd Tersteegen Prize 1996 was awarded jointly to:

Dr. W. R. Clark (Indianapolis/Ind., USA) for the work 'Plasma Protein Adsorption to Highly Permeable Hemodialysis Membranes' and

Dr. med. Jürgen Bachmann (Münster/Germany) for the work 'Hy-perhomocysteinemia and the Risk for Vascular Disease in Hemodialysis Patients'

The Deutsche Dialysegesellschaft niedergelassener Ärzte e.V (DDnÄ), the German Society of Nephrologists in Private Practices, wishes to announce to second Bernd Tersteegen Award. Dr. Bernd Tersteegen (Düsseldorf), 1995 deceased initiator and founder of the DDnÄ, dedicated himself fully to the improvement of patient treatment, above all with regard to the technical advancement of hemodialysis. The Bernd Tersteegen Award is intended to expedite internationally theoretical and practical research concerning kidney function insufficiency, especially in the field of patient therapy. Works should be orientated towards solving problems inherent in this sector, both from a theoretical and practical standpoint. Sponsored by Boehringer Mannheim GmbH (Mannheim/Germany), there will be an annual award of DEM 15,000 for the best evaluated entry.

Should the case arise, the award may be shared, but should however be focused upon one successful applicant. Applicants could be en-

compassed or engaged in any of the following: kidney failure and outpatient kidney therapy in the clinic, surgery or research physicians in laboratories, scientists or graduated engineers. Only original scientific theses either published between 1996 and 1997 or as yet still unpublished are acceptable and should be rendered in German or English. Wholly unacceptable are reviews, dissertations as also works already entered in other competitions. Should the participation be plural, the group should be represented by one speaker. However, all pertinent participants should be listed. Further there should be a curriculum vi-tae in a shortened form, as also a list of publications to date, enclosed. The evaluation will be made by a jury comprising a managing committee and members of the DDnÄ. The president of the DDn $\ddot{A}$ is automatically the chairman of the jury. In the case of an award not being made, the sum of money would be carried forward to the following year. No appeal is admitted. The award will be made during the annual meeting in 1997 of the DDnÄ on November 15,1997 in Mannheim. The award winner, who will be advised in good time, is obliged to be present. Applicants should submit five copies of their work by July 15,1997

to:

Deutsche Dialysegesellschaft niedergelassener Ärzte e.V Dr. med. Heinrich Kütemeyer, President Postfach 132304, D³/82050 Wuppertal, Germany

70

Kidney Blood Press Res 1997;20:64-70

Zawadzki 